\title{
Erratum to: Isolation and characterization of a novel $\varepsilon$-caprolactam-degrading microbe, Acinetobacter calcoaceticus, from industrial wastewater by chemostat-enrichment
}

\author{
Sasikumar Rajoo $\cdot$ Jung Oh Ahn • \\ Hong Weon Lee $\cdot$ Joon Ki Jung
}

Published online: 23 February 2014

(C) Springer Science+Business Media Dordrecht 2014

Erratum to: Biotechnol Lett (2013) 35:2069-2072

DOI 10.1007/s10529-013-1307-2

In the original publication of the article one of the co-author has missed to include one of his affiliation which has been included in this article.

The online version of the original article can be found under doi:10.1007/s10529-013-1307-2.

S. Rajoo · J. O. Ahn · H. W. Lee $(\bowtie) \cdot$ J. K. Jung Biotechnology Process Engineering Center,

Korea Research Institute of Bioscience and Biotechnology (KRIBB), 52 Oun-dong, Yusong, Daejeon 305-806,

Republic of Korea

e-mail: hwlee@kribb.re.kr

S. Rajoo

e-mail: sasi85@kribb.re.kr

J. O. Ahn

e-mail: ahnjo@kribb.re.kr

J. K. Jung

e-mail: jkjung@kribb.re.kr

\section{S. Rajoo}

University of Science and Technology (UST),

217 Gajeong-ro, Yuseong-gu, Daejeon 305-350,

Republic of Korea 